\title{
Conhecer não é representar: reflexões sobre a representação na Educação Ambiental
}

\author{
Angelica Vier Munhoz*
}

Jane Mazzarino**

\begin{abstract}
Resumo
O presente artigo busca problematizar o conceito de representação a partir dos aportes teóricos da Filosofia da Diferença. Dessa forma, serão analisados escritos produzidos durante oficinas do curso de Formação de Multiplicadores em Educação Ambiental, que integra o projeto de extensão Comunicação para Educação Ambiental, do Centro Universitário Univates. As oficinas, realizadas com professores da rede pública de ensino básico, constituíram-se em espaços de comunicação em que os interlocutores aventuram-se a ler para o outro seus escritos sobre memórias de vivências com a água. Estes espaços de aproximação de si mesmo e para com o outro potencializaram aprendizagens e o compartilhamento de significados sobre o mundo.
\end{abstract}

Palavras-chave: Representação. Educação ambiental. Água.

\footnotetext{
*Doutora em Educação pela Universidade Federal do Rio Grande do Sul (UFRGS). Professora titular do Centro de Ciências Humanas e Jurídicas e do Programa de Pós-graduação - Mestrado em Ensino e Mestrado Profissional em Ensino de Ciências Exatas - Centro Universitário Univates.

** Doutora em Educação pela Universidade do Vale do Rio dos Sinos. Professora adjunta do Centro Universitário Univates. Atua no Programa de Pós Graduação Ambiente e Desenvolvimento e nos cursos de graduação em Comunicação Social.
} 
O mundo é a minha representação Esta proposição é uma verdade para todo o ser vivo e pensante, embora só no homem chegue a transformar-se em conhecimento abstrato e refletido. A partir do momento em que é capaz de o levar a este estado, pode dizer-se que nasceu nele o espírito filosófico. Possui então a inteira certeza de não conhecer nem um sol nem uma terra, mas apenas olhos que veem este sol, mãos que tocam esta terra; numa palavra, ele sabe que o mundo que o cerca existe apenas como representação, na sua relação com um ser que percebe, que é o próprio homem. (SCHOPENHAUER, 2001).

Platão com sua teoria das ideias inaugura uma filosofia da representação. Estabelece dois tipos de imagens, dois tipos de cópias: a boa cópia, "o ícone que é uma imagem dotada de semelhança" (MACHADO, 2010, p. 45) e a má cópia, que implica uma perversão, uma imagem sem semelhança. "A cópia só se assemelha verdadeiramente a alguma coisa na medida em que se assemelha a ideia como modelo" (MACHADO, 2010, p. 45). Esse modelo platônico funda a representação. Uma representação então é uma entidade que está por outra entidade, isto é, uma coisa que está por outra coisa.

Platão cria os conceitos, mas coloca-os como "representando o incriado que os precede. Ele póe o tempo no conceito, mas este tempo deve ser o anterior" (DELEUZE; GUATTARI, 1992, p. 42), ou melhor dizendo, "no plano platônico, a verdade se póe como pressuposta, como já estando lá" (DELEUZE; GUATTARI, 1992, p.43). Dessa forma, Platão quer encontrar um critério seletivo que seja capaz de distinguir os verdadeiros problemas e os falsos.

Assim, o Platonismo é a doutrina de dois mundos, o sensível e o mutante como mundo da aparência e o supra-sensível e imutável como o mundo verdadeiro. Nesse domínio da representação, a cópia garante a similitude exemplar à essência do modelo, numa relação intrínseca ao seu fundamento, entre coisa e ideia, imagem e objeto.

Esse conceito de representação abriga as comparaçôes, registra a semelhança entre as coisas, sua decomposição em elementos idênticos e diferentes, acolhe as impressôes e a imaginação, desde o pensamento clássico. Contudo, estamos táo familiarizados com o pensamento da representação, 
com o pensamento por identidade e por semelhança que vemos os elementos de um sistema como dados naturais. E esses são os traços próprios do sistema de representação.

Imaginamos que a identidade na ideia e a semelhança na percepção são naturais. Olhamos para uma árvore e para outra e acreditamos que são semelhantes a uma arvore genérica - desprezamos como simples acidentes suas diferenças, as singularidades que as constituem e que as tornam seres absolutamente únicos. (FUGANTI, 2008, p. 91).

O pressuposto de que conhecer é representar atravessa o discurso da filosofia moderna concentrando seu interesse na noção de representação, uma vez que é um problema central para a filosofia moderna a relação cognoscitiva do sujeito e do mundo e, portanto, o alcance e as formas de representação.

Abdicamos assim do movimento de experimentar o mundo e experienciar a si mesmo. Pensar a formação desse pensamento fundado na representação torna-se necessário para desconstruí-lo em nós e fora de nós, sobretudo quando só se é capaz de perceber a imagem de si mesmo. "Subverter a filosofia da representação significa afirmar os direitos dos simulacros reconhecendo neles uma potência positiva, dionisíaca, capaz de destruir as categorias de original e cópia" (MACHADO, 2010, p. 48).

É nesse sentido que o presente artigo busca problematizar o conceito de representação a partir dos aportes teóricos da Filosofia da diferença. Para tal feito vai analisar escritos feitos durante oficinas do curso de Formação de Multiplicadores em Educação Ambiental, que integra o projeto de extensão Comunicação para Educaçáo Ambiental, do Centro Universitário Univates. Em três oficinas realizadas participaram 46 professoras da rede pública de ensino básico. Como parte da dinâmica, solicitava-se às participantes que escrevessem livremente sobre suas memórias e experiências em relação à água. Seus escritos eram lidos em uma roda de conversa.

Estas rodas de conversa se constituíram em espaços de comunicação em que os interlocutores aventuram-se a ler para o outro seus escritos sobre memórias de vivências com a água. Esses espaços de aproximação de si mesmo e para com o outro potencializaram aprendizagens e o compartilhamento de significados sobre o mundo. 


\section{As imagens do pensamento}

Grande parte da tradição filosófica é orientada por um pressuposto que afirma que entre o pensamento e a verdade haveria uma natural afinidade, de forma que o esforço do pensamento é sempre encontrar tal verdade. Assim, pensar as próprias representaçóes significa aprisionar-se em uma interioridade. No entanto, para Deleuze (2006), o verdadeiro problema do pensamento é o de como pensar a exterioridade. É isso que o torna diferente da mera reflexão. Sobre esse problema, Deleuze (2006) nos aponta para duas imagens do pensamento, uma baseada no modelo do reconhecimento ou da recognição, definida como moral, dogmática, representativa e outra baseada no modelo do encontro ou da experiência, nomeada como pensamento sem imagem.

Na primeira imagem, pensar significa substancialmente conhecer as coisas, os objetos, o mundo na sua verdadeira essência, ou melhor, significa responder corretamente a pergunta “O que é?". Se pensarmos a partir de Platão, ao entrar em contato com as coisas reais, conhecer seria perguntar à mente aquelas visóes ideais já conhecidas para encontrar a resposta verdadeira. Trata-se, pois, de lugares comuns dos quais se tem uma pré-compreensão, que nada mais é do que a opiniāo desses conceitos. Assim, pensar seria o exercício natural de uma faculdade e bastaria pensar "verdadeiramente" para pensar com veracidade. Além disso, o bom senso e o senso comum apresentam o pensamento como uma potência compartilhada por todos os homens de modo natural. É partindo do ideal do senso comum que Deleuze pensa o modelo da recognição, fundando-se nele, apresenta a imagem dogmática do pensamento.

O pensamento conceitual filosófico tem como pressuposto implícito uma imagem do pensamento, pré-filosófica e natural, tirada do elemento puro do senso comum. Segundo esta imagem, o pensamento está em afinidade com o verdadeiro, possui formalmente o verdadeiro e quer materialmente o verdadeiro. (DELEUZE, 2006, p. 192).

A segunda imagem opóe-se a primeira. Trata-se de um pensamento como encontro. Pensar nesse segundo plano nada tem a ver com reconhecimento ou com a verdade. Pensar diz respeito a encontrar signos que nos forçam a pensar (DELEUZE, 2003). É a violência do signo que leva o homem a criar conceitos, que o faz lutar contra os lugares comuns, a opinião, a doxa. O verdadeiro não é 
o elemento do pensamento, pelo contrário, somos constantemente desviados do verdadeiro por forças estranhas ao pensamento (corpo, paixóes, interesses). Esse pensamento não está representado, mas está sensível às variações que tem lugar em nossa cognição e se experimenta incessantemente, fugindo ao controle da representação. Deleuze propõe pensar um pensamento sem imagem, rompendo com a lógica da representação.

No primeiro modelo, fazemos perguntas que estejam em conformidade com as respostas que queremos suscitar, em conformidade com as proposiçóes que queremos convencer. "Uma interrogação é sempre calcada sobre respostas possíveis de serem dadas, sobre respostas prováveis ou possíveis" (DELEUZE, 2006 , p. 225). No entanto, enquanto a interrogação abre uma via, a solução desmancha o problema. É preciso então desembaraçar-se da imagem dogmática do pensamento que decalca os problemas sobre proposiçóes correspondentes, que sevem de respostas e/ou soluçóes. Dessa forma, os problemas não são dados, mas devem ser constituídos e investidos em campos simbólicos que the são próprios. "Uma soluçáo tem sempre a verdade que merece de acordo com o problema a que ela corresponde; e o problema tem sempre a soluçáo que merece de acordo com sua própria verdade ou falsidade, isto é, de acordo com seu sentido" (DELEUZE, 2006, p. 229).

Assim, o problema não é uma forma percebida, não é uma imagem que já está na representação, é antes uma potência de criar novas imagens. É nesse sentido que a invenção de problemas é "a potência que a cognição tem de diferir de si mesma, de transpor seus próprios limites" (KASTRUP, 2007, p. 65). Implica uma duração, uma preparação que ocorre no avesso das formas visíveis. Problematizar é, pois, bifurcar, criar caminhos divergentes e imprevisíveis, entrar na espessura do problema (KASTRUP, 2007).

Um problema não existe fora de suas soluçôes. Mas, em vez de desaparecer, ele insiste e persiste nas soluçóes que o recobrem. Um problema se determina ao mesmo tempo em que é resolvido; mas sua determinação não se confunde com a solução: os dois elementos diferem por natureza, e a determinaçáo é como que a gênese da solução concomitante (DELEUZE, 2006, p. 235).

A representação e a cognição inventiva são "dois modos de estar no mundo, de estabelecer relação consigo e com a própria atividade de conhecer" 
(KASTRUP; TEDESCO; PASSOS, 2008, p. 12). Assim conhecer é diferente de representar ou reconhecer e, portanto, não pensamos quando reconhecemos.

\section{O pensamento como experiência/experimentação}

Enquanto as experiências de recognição "permitem o reconhecimento prático ou consciente de um objeto: isso é um livro; posso atravessar a rua, aqui há uma árvore" (KASTRUP, 2007, p. 68), caracterizando-se por uma utilidade na vida prática, nos colocando a funcionar pelo senso comum e pelas banalidades da vida cotidiana, há experiências nas quais nossas relaçôes com o mundo apresentam-se problemáticas. Nessas, os esquemas de recognição revelam-se inadequados ou impotentes para assimilar o que nos apresenta. Tais experiências indicam a impotência dos esquemas de recognição e convocam a uma invenção cognitiva.

A cognição inventiva, portanto, é uma prática de experimentação e é nessa experimentação que se dá o encontro, mais ou menos inesperado, com a matéria. A experimentação é o acontecimento, a partir do qual se infere a existência de outra coisa que ainda não está dada pelos sentidos. A experiência é da ordem do acontecimento e é essa ideia que acompanha Deleuze na sua formulação do pensar como cogniçáo e náo recognição ou reproduçãa. $\mathrm{O}$ acontecimento opera ao lado do pensamento como potência de invençáo, uma relaçáo de imanência entre o pensamento e o mundo. Em meio às experiências do devir, o novo é experimentado: "[...] toda interação, todo acoplamento, interfere no funcionamento do sistema nervoso, por causa das mudanças estruturais que nele desencadeia. Toda experiência é modificadora, em especial em relação a nós, embora às vezes as mudanças não sejam completamente visíveis" (MATURANA; VARELA, 2001, p. 189).

Kastrup (2007), ao interpretar a obra de Maturana e Varela, explica que para os autores a evoluçáo com base na reprodução significa pensar a partir do organismo com seu código genético e não do movimento criador. Para os autores tudo começa com perturbaçôes e não com transmissão de informaçóes.

Percebemo-nos num mútuo acoplamento lingüístico, náo porque a linguagem nos permita dizer o que somos, mas porque somos na linguagem, num contínuo ser nos mundos lingüísticos e semânticos que geramos com os outros. Vemo-nos nesse acoplamento, não como a origem 
de uma referência nem em relação a uma origem, mas como um modo de contínua transformação no devir do mundo lingüístico que construímos com os outros seres humanos. (MATURANA; VARELA, 2001, p. 257).

Quando o organismo é afetado não se pode dizer que ele represente o meio, mas algo nele é problematizado, continua Kastrup (2007), na sua interpretação dos autores. Trata-se, portanto, de composição, agenciamento e não de acomodação. Adaptar-se, para Maturana e Varela (2001), é tirar partido do meio, viabilizando a continuidade da vida. Mas a adaptação não é o motor da evoluçáo, não explica os movimentos da vida, responde apenas pelas formas nas quais os movimentos da vida se detêm ou desaceleram. A adaptação é assim, compatibilidade com o meio e não adequação ao meio ou representação do meio. A noção de representação, segundo Varela (1994), é ontológica e epistemologicamente insustentável nas ciências da cognição contemporâneas.

Para pensar em tal situação, Varela (apud KASTRUP, 2007, p. 172), traz como exemplo a aprendizagem de um instrumento musical, a flauta. Para descrever esse processo de aprendizagem o autor afirma que no início o corpo funciona comandado pela mente, ou seja, o aprender começa pela representação, pelo simbólico. Mas logo chama a atenção para "aprender a tocar flauta não é seguir regras”. A aprendizagem então só se efetua quando a relação simbólica é transformada em acoplamento direto, eliminando o intermediário da representaçấo, ou seja, "aprender não é adequar-se a flauta, mas agenciar-se com ela” (KASTRUP, 2007, p. 172). Aprender um instrumento é vivenciar um vazio de representaçáo, estar sem chão, criar no inexistente um modo de expressão, experienciar uma vertigem dos sentidos.

Enquanto o mundo da representaçáo é impotente para pensar a diferença, a cogniçẫo inventiva primazia pela diferença, pois não há possibilidade da imagem se fixar e restam as práticas de criaçáo, de ruptura ao modelo e de composição de novas possibilidades que se efetivam a partir do aprender: "Aprender é, então fazer a cognição diferenciar-se permanentemente de si mesma, engendrando, a partir daí, novos mundos" (KASTRUP, 2005, p. 1282).

Por causa da nossa herança biológica comum temos os fundamentos de um mundo comum [...]. De nossas heranças lingüísticas diferentes surgem todas as diferenças de mundos culturais, que como homens podemos viver 
e que, dentro dos limites biológicos, podem ser táo diversas quanto se queira (MATURANA; VARELA, 2001, p. 265).

Assim, problematizar é criar caminhos divergentes ao passo que solucionar problemas é ser capaz de solucionar novas formas de existência. O domínio cognitivo não é um domínio de representação, mas "um domínio experimental e emergente das interações e dos acoplamentos dos organismos" (KASTRUP, 2007, p. 148).

\section{Conhecer não é representar}

A cultura pode ser o movimento de aprender, a aventura que encadeia uma memória, uma sensibilidade, um pensamento, mas pode também apenas "adestrar o espírito" (NIETZSCHE, 1998). Uma cultura não pode estar subordinada ao saber. $\mathrm{O}$ aprender é o intermediário entre o saber e o não-saber, a passagem viva de um a outro.

No curso de multiplicadores em Educação Ambiental, a pesquisadora solicitou aos participantes que escrevessem sobre as suas experiências com a água. Algumas dessas escrituras foram destacadas neste artigo para serem analisadas:

Considero a água um bem precioso que representa o início, meio e o fim da manutençáo da vida (R).

Hoje percebo que muitos estão preocupados com este líquido precioso que nos traz muitos benefícios e necessitamos dele para sobreviver. Então vamos juntos cuidar e preservar deste bem que recebemos da natureza. (L).

A água para mim lembra as necessidades diárias de sobrevivência. Ao levantarmos precisamos fazer a higiene da face e bucal, descarga do vaso, café da manhä, lavar a louça, lavar a roupa, limpeza da casa, regar as plantas, etc. Ou seja, não existe sobrevivência sem água, água é vida (Al).

O nosso planeta é composto $70 \%$ de água, oceano, lençóis d'água, mares, lagos, lagoas, açudes, rios, riachos, vertente, olho d'água, córrego, neblina, orvalho, neve, chuva, dentre 
outros. Todas essas fontes d'água são indispensáveis para nós, seres humanos. (Lá).

A água está presente em todos os momentos de nossas vidas, desde que nascemos até o dia em que morremos (B).

É preciso uma mudança de comportamento de todos para haver mudança nas nossas atitudes perante o meio-ambiente e garantir a abundancia e a saúde desse recurso natural tão descuidado. (Mi).

As memórias que tenho sobre a água são muito boas, pois de todos os temporais, enchentes, desastres ecológicos relacionados com a água, nenhum deles atingiu a minha familia. (J).

Os usos da água representam a maneira como o homem se relaciona com o meio ambiente nas questóes que dizem respeito a si próprio e ao próximo. (Ri).

Podemos perceber nas escritas acima que as relaçóes efetuadas sobre a água dizem respeito a uma universalidade que aparece sob a forma da representação ou da recognição. Ao ser convidado a falar/escrever sobre "as suas experiências sobre a água" os pressupostos aparecem como naturais e pré-conceituais, com a forma de "todo mundo sabe", ou seja, sob a forma do senso comum.

Tomada como objeto de representação, a diferença não aflige o pensamento, apenas o mantém ocupado com a própria imagem. A imagem dogmática do pensamento considera qualquer problema como algo dado, cuja soluçáo também está dada nele e o anula ou neutraliza assim que é encontrada. Ao buscar entender alguma coisa, necessita-se do representado, de tal forma que ao ouvir ou ler uma palavra isolada, automaticamente se procura uma relação desta com objeto por ela representado.

Da mesma forma, o pensamento pressupóe uma tendência para o verdadeiro e essa busca da verdade reduz o pensamento ao já conhecido. Ao pressupor o que se pretende explicar, elimina-se a imprevisibilidade de seus resultados e consequentemente a produção da novidade. Representar é, pois, buscar uma resposta compartilhada socialmente por meio do exercício racional, experimentar é deixar vir nova possibilidade. 


\section{A questão da água como experiência ou como cognição inventiva}

Se a bagagem cultural diz respeito à reprodução dos saberes e é aquilo que todos podem adquirir, a experiência envolve sempre a singularidade. Crer que a água é vital para a vida, que é um bem precioso, que deve ser preservada, não constituem um problema $\mathrm{e}$, portanto, não possibilitam a experiência ou abrem campos de pensamento.

$\mathrm{Na}$ experiência não se pode preocupar em adequar o conceito a alguma coisa ou a um estado de coisas. A experiência não possibilita imagens, mas tem relação com a criação, com o pensamento nômade. É na experimentação que o pensamento se prolifera e voa em movimentos finitos e infinitos.

O que pode arrancar o pensamento de sua inércia é o encontro com o inusitado, com a experiência que força o pensamento a sair de si. Ao sair da representação, do já conhecido, o pensamento é capaz de voar e criar o novo. É dessa forma que podemos perceber as falas/escritas abaixo:

Minha vivência com a água me remete a infância. Havia um pequeno córrego no potreiro de meu pai onde eu e meus dois irmãos passávamos boa parte das tardes de verão $(\mathrm{M})$.

Também recordo do primeiro banho dos filhos, do primeiro mergulho, dos banhos de chuva e brincadeiras que faziamos quando éramos pequenos. (Ma).

Quando chovia nos reuníamos na rua para fazer aquela festa nas valetas [...]. (D).

Dias de inverno frio e chuvoso, sair da casa, pegar a moto e mesmo com capa de chuva chegar ao destino encharcada. (G).

O arroio transbordava e a enchente levava a produção e soja ou milho na várzea, causando prejuizos econômicos. (E).

Tínhamos uma vizinha que fazia doce de laranja azeda e para 'curtir' a laranja, ela as colocava em um saco de algodão e amarrava em um galho que pudesse ficar mergulhado na água corrente do Arroio Sarafano alguns dias. (Bi).

Lembro na minha infância a falta de água no verão quando o poço secava, pois havia uma rocha no fundo que não se conseguia perfurar. Então tínhamos que pegar água no vizinho para beber e a mãe ia até o arroio lavar as roupas e 
trazia a água para casa do arroio em tonéis para os animais com a carroça. (P).

$\mathrm{Na}$ década de 50, convivi até os 8 anos de idade com enchentes, meu pai trabalhava com venda de areia no rio Vacacai, entre as cidades de São Sapé e Santa Maria e morávamos próximo, mais ou menos $1 \mathrm{~km}$ e $1 / 2$ deste rio e no inverno o rio transbordava e chegava até nós. (J).

O saber aprendido não é puramente conceitual, traduzível, decifrável, linear, mas se constitui por contágios, encontros e devires. O corpo que aprende, inventa, experimenta, flutua, corre, voa. Deixa-se aprender sem se preocupar com o que, onde, como, para que está aprendendo. Aquilo que não pensa é aquilo que lhe escapa, pois não está preso à representação e sim às experiências e experimentaçôes vividas.

Greiner (2010, p. 76), a partir de Alva Noë, propóe pensar que "ter uma experiência é ser confrontado com um modo possível de mundo. O conteúdo da experiência e o conteúdo do pensamento são os mesmos". A experiência é um experimentar significados mediados pela emoção e pelo sentimento. A autora entende que os significados emergem das conexóes entre organismo e ambiente: "A vida humana poderia ser entendida como a arte de dar significado às nossas experiências corporais" (GREINER, 2010, p. 92). Do mesmo modo diz Valverde (2010, p. 70, grifo do autor): "E é o corpo - esse meio, ao mesmo tempo natural, cultural e histórico de transcendência - que torna presente a possibilidade de toda experiência".

Brincávamos de mergulhar e contar o tempo. Quis ser a valentona e ficar mais tempo possivel. Foi quando não aguentei e quase me afoguei. (L).

A emoção quando via a lagoa foi grande, achei que já tinha chegado ao mar. (A).

[...] pescarias com peixe frito à beira do riacho. (J).

[...] encontrávamos argila com a qual moldávamos objetos incriveis. (M).

A água em contato com as pedras era limpinha e onde ela caía ela fazia barulho. Ali pescávamos e nos banhávamos. (P).

Granizo para comer. (J).

[...] uma troca de carinho eterno entre mäe e filho no primeiro banho após seu nascimento. (L). 
Nas falas dos participantes, parece não haver um saber anterior que regula e engessa o pensamento ou busca uma solução na recognição, mas a experimentação de determinadas experiências, a criação de problemas e a busca de soluções alternativas e, sobretudo, inventivas, mostram aprendizagens sobre a água que são da ordem da singularidade e de um pensamento que se agencia a diferença.

Enquanto a relação entre problemas e o aprender é mediada pelos signos responsáveis por forçar o pensamento a pensar, a relação entre problema e saber se rege por um método que determina a soluçấo e inviabiliza o aprendiz de intervir no problema. A produçâo do saber é muitas vezes absorvida pela lógica da representação, na qual se tenta produzir um conhecimento insípido, neutro e eterno.

O pensar convida a seguir um caminho bifurcante, onde inventar problemas e produzir soluçóes esteja ligado à experimentação. Para isso é preciso desconfiar das certezas, das formas e fórmulas prontas e inquestionáveis, das ideias-clichês.

Enfim, tal política inventiva deve percorrer em nós e fora de nós desencadeando forças que propulsionam o movimento criador do pensamento, o que pode resultar em novas práticas e problematizaçóes.

\section{Conclusão}

Entre a potência de transformação e a tentativa de manutenção do saber há uma constante tensão. Sabemos que o mundo da representação é importante e fundamental para a nossa inteligibilidade e comunicação, no entanto, é possível enxergar além desse plano. Abrir-se à desconfiança, a dúvida, torna-se difícil à medida que estabelecemos divisóes claras entre o certo e o incerto, a forma e o informe, a verdade e a simulação. No entanto, os conceitos não são eternos, as ideias são temporais, as verdades são passageiras. "Um conceito tem sempre a verdade que lhe advém em função das condições de sua criação". (DELEUZE; GUATTARI, 1992, p. 40).

Quando rompemos com a lógica da representação, procuramos outro modo de pensar, um pensar mais inventivo, mais problematizador, que fuja do senso comum e dos clichês.

Os relatos das experiências das professoras explicitaram representaçóes e pensares inventivos. Especialmente em relação aos pensares inventivos, nas rodas de conversa e com pesquisadores, demonstrou sua potência de despertar memórias afetivas em quem as lê, abrindo encontros inusitados com o já vivido 
em um e outro, redescobrindo emoçóes singulares que, ressurgentes, provocam devires. Essa estética das memórias de experiências compartilhadas, por ser perturbadora dos sentidos, convida à invenção cognitiva.

Quando não se reduziu a reproduzir representaçóes relacionadas ao senso comum, a escritura sobre as memórias com a água revelou afetos, percepçóes, emoçóes e sensibilidades. Desse modo, o exercício da escrita enquanto um processo comunicacional multidimensional (revelador de sentido pra si mesmo, para o outro e sobre o mundo), constituiu-se em si mesmo uma experiência estética. Para Leal, Mendonça e Guimarães (2010, p. 14): “[...] a comunicação está na base da experiência sensível, naquilo que nela há de compartilhável".

E esse fenômeno prescindiu de mídias de última geração, já que se deu por meio das tecnologias mais elementares: a escritura, com uso de canetas em folhas de papel, e sua manifestação corporal por meio da voz, que gerou escutas atentas nas rodas de conversa. Portanto, as estratégias visuais e verbais utilizadas nas rodas de conversas foram as primordiais: a voz e o imaginário.

Ao ser contada, a experiência é revivida como memória comunicada, podendo abrir-se a novos sentidos por quem a viveu, ser reconstruída, reorganizada, reterritorializada. Mas também corre o risco de ser esvaziada, como aponta Queré (2010, p. 25), para quem a vivência se vive, pois ao descrevê-las se esvaziaria de sentido: "[...] a linguagem não se aplica as nossas sensaçóes, aos nossos estados internos ou as nossas vivências, como faz aos estados de coisas, aos objetos ou aos acontecimentos do mundo que nos cerca”.

Enfim, os escritos sobre as memórias de experiências hídricas, pensados enquanto um acontecimento, demonstram ter uma tripla potência: de afetaragir sobre seus escritores, como também de reterritorializar seus sentidos e os do outro ou, ainda, de esvaziar-se de sentido ao serem partilhados.

\section{REFERÊNCIAS}

DELEUZE, Gilles. Proust e os signos. 2. ed. Rio de Janeiro: Forense Universitária, 2003.

DELEUZE, Gilles. Diferença e repetição. Rio de Janeiro: Graal, 2006.

DELEUZE, Gilles; GUATTARI, Félix. O que é Filosofia. Rio de Janeiro: 34, 1992. FUGANTI, Luiz. Saúde, desejo e pensamento. São Paulo: Hucitec, 2008. 
GREINER, Christine. O corpo em crise: novas pistas e o curto circuito das representaçôes. São Paulo: Annablume, 2010.

KASTRUP, Virginia. Políticas cognitivas na formação do professor e problema do devir-mestre. Educação e Sociedade. Campinas, SP, v. 26, n. 93, p. 1273-1288, 2005.

KASTRUP, Virginia. A invenção de si e do mundo: Uma introdução do tempo e do coletivo no estudo da cognição. 2. ed. Belo Horizonte: Autêntica, 2007.

KASTRUP, Virginia; TEDESCO, Silvia; PASSOS, Eduardo. Politicas da cognição. Porto Alegre: Sulina, 2008.

LEAL, Bruno Souza; MENDONÇA, Carlos Camargo; GUIMARÁES, César (Org.). Entre o sensivel e o comunicacional. Belo Horizonte: Autêntica, 2010. p. 7-15.

MACHADO, Roberto. Deleuze, a arte e a filosofia. 2. ed. Rio de Janeiro: Jorge Zahar, 2010.

MATURANA, Humberto R. VARELA, Francisco J. A árvore do conhecimento: as bases biológicas da compreensão humana. 6. ed. São Paulo: Palas Athena, 2001.

NIETZSCHE, Friedrich. Genealogia da moral. 3. ed. São Paulo: Companhia das Letras, 1998.

QUERÉ, Louis. O caráter impessoal da experiência. In: LEAL, Bruno Souza; MENDONÇA, Carlos Camargo; GUIMARÃES, César (Org.). Entre o sensivel e o comunicacional. Belo Horizonte: Autêntica, 2010. p. 19-38.

SCHOPENHAUER, Arthur. O mundo como vontade e representação. Rio de Janeiro: Contraponto, 2001.

VALVERDE, Monclar. Comunicação e experiência estética. In: LEAL, Bruno Souza; MENDONÇA, Carlos Camargo; GUIMARÃES, César (Org.). Entre o sensivel e o comunicacional. Belo Horizonte: Autêntica, 2010. p. 57-71.

VARELA, Francisco. Conhecer: as ciências cognitivas: tendências e perspectivas. Lisboa: Instituto Piaget, 1994. 


\section{To know is not to represent: an experience in environmental education}

\section{Abstract}

This paper seeks to problematize the concept of representation from the theoretical contributions of the Philosophy of Difference. For this purpose it analyses writings carried out in workshops of the Training Courses for Multipliers in Environmental Education, which integrates the Communication for Environmental Education extension project of Centro Universitário Univates. The workshops, carried out with Elementary and High School teachers of the public schools net, constituted spaces of communication where interlocutors adventured to read for others their writings about memories of experiences with water. These spaces of approaching of oneself and to others potentiated learning as well as the sharing of meanings about the world.

Keywords: Representation. Environmental education. Water.

\section{Conocer no es representar: una experiencia en la Educación Ambiental}

\section{Resumen}

El presente artículo discute el concepto de representación a partir de los aportes teóricos de la Filosofía de la Diferencia. Para tal fin se analizaron los textos escritos en los talleres del curso de Formación de Multiplicadores en Educación Ambiental, organizado por el proyecto de extensión en Comunicación para Educación Ambiental, del Centro Universitario Univates. Los talleres, realizados con profesores de la red pública de enseñanza básica, se constituyeron en espacios de comunicación entre los interlocutores que se aventuraron a leerle al "otro" sus escritos acerca de las memorias de vida con el agua. Estos espacios de aproximación hacia sí mismo y hacia el otro desencadenaron el aprendizaje y el intercambio de significados sobre el mundo.

Palabras claves: Representación. Educación ambiental. Agua.

\section{Angelica Vier Munhoz}

E-mail: angelicavmunhoz@gmail.com,

Jane Mazzarino

E-mail: janemazzarino@gmail.com

Recebido em: 18/10/2012

Versão final recebida em: $12 / 8 / 2013$

Aprovado em: 17/8/2013 
1 